\title{
Effect of Flow Rate on Turbulence Dissipation Rate Distribution in a Multiphase Pump
}

\author{
Zongliu Huang, Guangtai Shi *, Xiaobing Liu * and Haigang Wen
}

check for updates

Citation: Huang, Z.; Shi, G.; Liu, X.; Wen, H. Effect of Flow Rate on Turbulence Dissipation Rate Distribution in a Multiphase Pump. Processes 2021, 9, 886. https:// doi.org/10.3390/pr9050886

Academic Editor: Wei Wang

Received: 27 April 2021

Accepted: 13 May 2021

Published: 18 May 2021

Publisher's Note: MDPI stays neutral with regard to jurisdictional claims in published maps and institutional affiliations.

Copyright: (c) 2021 by the authors. Licensee MDPI, Basel, Switzerland. This article is an open access article distributed under the terms and conditions of the Creative Commons Attribution (CC BY) license (https:// creativecommons.org/licenses/by/ $4.0 /)$.
Key Laboratory of Fluid and Power Machinery, Ministry of Education, Xihua University, Chengdu 610039, China hzl27@mail.xhu.edu.cn (Z.H.); vincentbo@vip.163.com (H.W.)

* Correspondence: sgtaixh@126.com (G.S.); liuxb@mail.xhu.edu.cn (X.L.); Tel.: +86-138-8228-0482 (G.S.); +86-139-8203-1333 (X.L.)

\begin{abstract}
The turbulence dissipation will cause the increment of energy loss in the multiphase pump and deteriorate the pump performance. In order to research the turbulence dissipation rate distribution characteristics in the pressurized unit of the multiphase pump, the spiral axial flow type multiphase pump is researched numerically in the present study. This research is focused on the turbulence dissipation rate distribution characteristics in the directions of inlet to outlet, hub to rim, and in the circumferential direction of the rotating impeller blades. Numerical simulation based on the RANS (Reynolds averaged Navier-Stokes equations) and the $k$ - $\omega$ SST (Shear Stress Transport) turbulence model has been carried out. The numerical method is verified by comparing the numerical results with the experimental data. Results show that the regions of the large turbulence dissipation rate are mainly at the inlet and outlet of the rotating impeller and static impeller, while it is almost zero from the inlet to the middle of outlet in the suction surface and pressure surface of the first-stage rotating impeller blades. The turbulence dissipation rate is increased gradually from the hub to the rim of the inlet section of the first-stage rotating impeller, while it is decreased firstly and then increased on the middle and outlet sections. The turbulence dissipation rate distributes unevenly in the circumferential direction on the outlet section. The maximum value of the turbulence dissipation rate occurs at 0.9 times of the rated flow rate, while the minimum value at 1.5 times of the rated flow rate. Four turning points in the turbulence dissipation rate distribution that are the same as the number of impeller blades occur at 0.5 times the blade height at 0.9 times the rated flow rate condition. The turbulence dissipation rate distribution characteristics in the pressurized unit of the multiphase pump have been studied carefully in this paper, and the research results have an important significance for improving the performance of the multiphase pump theoretically.
\end{abstract}

Keywords: multiphase pump; turbulence dissipation rate; flow rate; pressurized unit; numerical simulation

\section{Introduction}

The demand for energy is growing fast with the development of the economy and industry, thus the development of the deep-sea oil field has become an inevitable trend of social development. Deep-sea oil and gas resources are usually a mixture of oil, gas, and water, which is a kind of multiphase fluid in truth. The multiphase pump is one of the core equipment in the process of transporting such a multiphase medium [1,2]. Otherwise, micro-/nanobubbles can be generated with the aid of a multiphase pump through different formation mechanics [3-6]. It has been widely employed in numerous industries, ranging from chemistry to biology [7-9].

A certain energy loss is often accompanied during the transfer process due to the particularity of the structure of the multiphase pump and the complexity of the multiphase media flow $[10,11]$. The turbulence dissipation rate can reflect not only the energy loss in the pressurized stage directly, but also the stability and uniformity of the flow field in 
the pressurized stage, so it has become one of the researches focus. Numerical simulation and experimental testing methods were used mainly in the existing research on the multiphase pump.

In numerical simulation research, Jinya Zhang et al. [12] researched and analyzed the multiphase pump and obtained the flow characteristics and flow rate parameters at the impeller inlet under different operating conditions. Liu Xiaobin et al. [13] carried out the numerical simulations on the transient flow rate and dynamic characteristics of the multiphase pump and found that the flow rate conditions could be changed by the cavitation, to aggravate the unstable flow rate. Shi Guangtai et al. [14] researched the phase distribution and pressure fluctuation in tip clearance in a multiphase pump. Wenwu Zhang et al. [15] developed a Euler two-fluid model to analyze the phase interaction in the multiphase pump. In addition, more related research was carried out on the multiphase pump with numerical calculations, to obtain some valuable conclusions [16-22].

In the experimental research, the gas-liquid flow patterns and the flow characteristics around the impeller on the inlet section of the three-stage rotary power multiphase pump were researched with visual experiments under different operating conditions [23]. Verde W.M. [24] built an experiment facility that would allow visualization inside the impeller to study the gas-liquid flow patterns inside a centrifugal pump impeller, the effects of the gas-liquid flow pattern, bubble changes, and the flow in the impeller on the performance of the centrifugal pump were researched under different operating conditions. In addition, some related research was carried out on the multiphase pump with experimental methods, to obtain some valuable conclusions [25-27].

At present, the study of the multiphase pump is mainly focused on the internal flow mechanism. It is difficult to measure the detail turbulent flow field due to the complexity of the structure of the pump, so there are few research studies on the turbulence dissipation rate in the multiphase pump. However, there are many research studies on the turbulence dissipation rate in other kinds of pumps. The PIV (Particle Image Velocimetry) technique was employed to study the flow characteristics in pumps and the turbulent kinetic energy dissipation rate characteristics were analyzed. N. Ertürk [28] studied the flow characteristics of an external gear pump with time-resolved PIV and estimated the dissipation rate of the turbulent kinetic energy. K.V. Sharp [29] measured the structure of turbulent motions in a region surrounding the blade tips of a Rushton turbine mixer by PIV. Other important research about the turbulence characteristics was also been carried out by PIV technologies [30-32].

In this paper, the turbulence dissipation rate in a multiphase pump is researched numerically. This research is focused on the effect of flow rate on the turbulence dissipation rate distribution characteristics. In order to ensure the reliability of the research results and taking into account the limits of simulation cost, only at different flow rates involved in engineering practices were followed for the research, to obtain the changes of turbulence dissipation rate with flow rate in the multiphase pump. The main research objective is the mechanism of energy lose in the multiphase pump, and to provide a theoretical basis for the design method of the multiphase pump.

\section{Research Object}

A six-stage spiral axial flow type multiphase pump developed by the authors is selected as the research object in the present study. The pump has a vane type structure and has the advantages of simple structure, small volume, large flow rate and it can be used for transporting fluid with a small number of particles compared with the positive displacement pump [2,33]. The main design parameters are as follows: design flow rate $Q=110 \mathrm{~m}^{3} / \mathrm{h}$, rotational speed $n=3000 \mathrm{rpm}$, impeller blades and diffuser blades are 4 and 9 , respectively. Figure 1 shows the axial flow spiral oil-gas multiphase pump, which is mainly composed of the suction chamber, the pressurized units, and the extrusion chamber. The pressurized units are composed of the rotating impeller and the static impeller. 


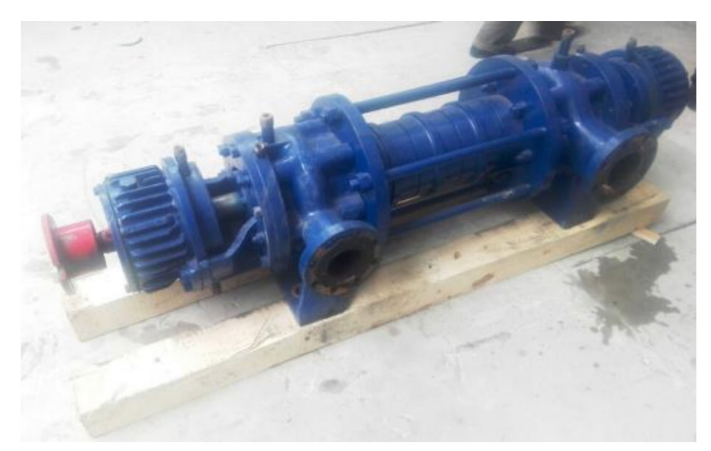

Figure 1. The six-stage multiphase pump.

\section{Numerical Methods and Setting}

\subsection{Governing Equations, Numerical Methods, and Boundary Conditions}

The turbulent flow in the multiphase pump is very complex, three-dimensional, random, and irregular, and changes with time and space, carrying countless vortices with different sizes and shapes depending on the geometric space of the flow field. In order to simulate such a flow accurately and efficiently, the RANS (Reynolds averaged NavierStokes) equations combined with $k-\omega$ SST (Shear Stress Transport) turbulence models were employed in this research, because of their good stability and applicability and which have been confirmed in a large number of examples in engineering practice and scientific research [34,35]. As the pump is one of rotating machinery, a two-dimensional simulation will reduce the accuracy of the results and lose lot information of the flow field, so a fully three-dimensional simulation is carried out in the present study as most researchers have done. Pure water is selected as the fluid medium in the pump in the present study, the compressibility of fluid has been neglected. The fluid properties are listed in Table 1.

Table 1. Fluid properties.

\begin{tabular}{cc}
\hline Variables & Value \\
\hline density $\rho /\left(\mathrm{kg} / \mathrm{m}^{3}\right)$ & 1000.0 \\
kinematic viscosity $\nu /\left(\mathrm{m}^{2} / \mathrm{s}\right)$ & $1.01 \times 10^{-6}$ \\
compressibility & None \\
\hline
\end{tabular}

The RANS equations are Equations (1) and (2).

$$
\begin{gathered}
\frac{\partial \overline{u_{i}}}{\partial x_{i}}=0 \\
\overline{u_{j}} \frac{\partial \overline{u_{i}}}{\partial x_{j}}=-\frac{1}{\rho} \frac{\partial p}{\partial x_{i}}+\frac{\partial}{\partial x_{j}}\left(v \frac{\partial \overline{u_{i}}}{\partial x_{j}}-\overline{u_{i}^{\prime} u^{\prime}}\right)
\end{gathered}
$$

In the above equations, $i, j=1,2,3 . \overline{u_{i}}$ is the averaged component of velocity. $p$ denotes the pressure. $\rho$ is the density of fluid. $v$ is the kinematic viscosity. $u_{i}{ }^{\prime}$ and $\overline{u^{\prime}{ }_{i} u^{\prime}}{ }_{j}$ denote the fluctuating component of flow velocity and Reynolds stress tensor, respectively.

The $k-\omega$ SST turbulence model is a two-equation model, including turbulent kinetic energy Equation (3) and turbulent frequency Equation (4).

$$
\begin{gathered}
\frac{\partial\left(\rho \overline{u_{i}} k\right)}{\partial x_{i}}=P_{k}-\beta^{*} \rho k \omega+\frac{\partial}{\partial x_{i}}\left[\left(\rho v+\sigma_{k} \rho v_{t}\right) \frac{\partial k}{\partial x_{i}}\right] \\
\frac{\partial\left(\rho \overline{u_{i}} \omega\right)}{\partial x_{i}}=\left[\frac{5}{9} F_{1}+0.44\left(1-F_{1}\right)\right] \frac{P_{k}}{v_{t}}-\beta \rho \omega^{2} \\
+\frac{\partial}{\partial x_{i}}\left[\left(\rho v+\sigma_{\omega} \rho v_{t}\right) \frac{\partial \omega}{\partial x_{i}}\right]+2\left(1-F_{1}\right) \frac{\rho \sigma_{\omega 2}}{\omega} \frac{\partial k}{\partial x_{i}} \frac{\partial \omega}{\partial x_{i}}
\end{gathered}
$$


The calculation of the Reynolds stress is based on the Boussinesq hypothesis in Equation (5) [36].

$$
\overline{u_{i}^{\prime} u^{\prime}}{ }_{j}=-v_{t}\left(\frac{\partial \overline{u_{i}}}{\partial x_{j}}+\frac{\partial \overline{u_{j}}}{\partial x_{i}}\right)+\frac{2}{3} k \delta_{i j}
$$

where the eddy viscosity is calculated by Equation (6).

$$
v_{t}=\frac{\alpha_{1} k}{\max \left(\alpha_{1} \omega, \sqrt{2 S_{i j} S_{i j}} F_{2}\right)}
$$

The more detailed parameters in the above equations can be found in reference [37]. Governing equations were solved using finite volume method by the CFD software ANSYS CFX. High resolution scheme was used to discretize the governing equations. The criterion for solution convergence was chosen based on the root mean square method and was set equal to $10^{-5}$.

The inlet and outlet boundary conditions were set as follows: apply a constant pressure at the pump outlet, and a constant mass flow rate at the inlet. All walls of suction chamber, extrusion chamber, rotating impeller, and static impeller are set as the non-slip wall. The wall of the rotating impeller was rotated and the other walls were stationary in the coordinate system.

\subsection{Numerical Method Verification}

An experimental test was carried out to verify the reliability of the numerical results. The experimental test system for the multiphase pump included the motor, multiphase pump, gas-liquid mixing tank, lubrication system, cooling system, control system, water supply system, gas supply system, test system, pipeline, valves, and etc. The experimental system for the multiphase pump is shown in Figure 2.
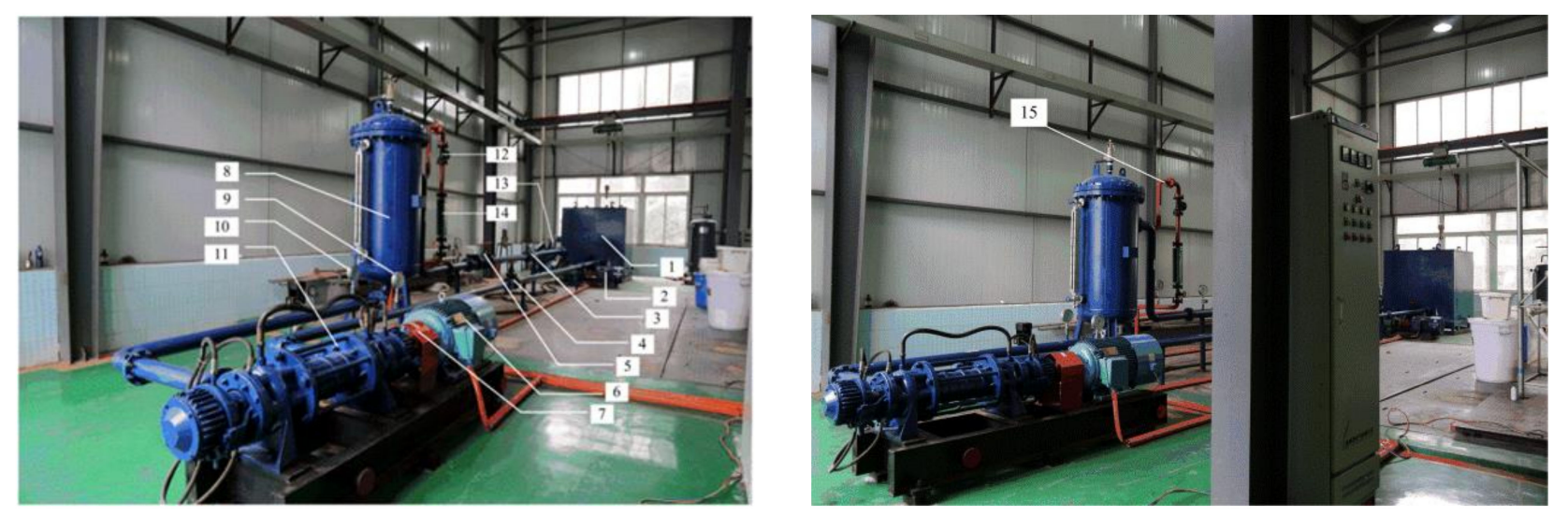

Figure 2. The multiphase pump test system. 1 . Water tank; 2 . Water supply pump; 3 . Flow meter; 4 . Outlet valve; 5 . Inlet valve; 6 . The motor; 7 . Torque meter; 8 . Gas-liquid mixing tank; 9. Outlet pressure gauge; 10. Inlet pressure gauge; 11. Multiphase pump; 12. Check valve; 13. Air compressor; 14. Gas flow meter; 15. Gas pipeline.

The numerical results are compared with the experimental results at the same conditions. Figure 3 shows the comparison of the experimental data and simulation results, and it can be seen that the change tendencies in the numerical results and the experimental results are consistent, the water head and the efficiency of the optimal points of relative errors are both around $4.1 \%$. The maximum relative error of the head and the efficiency is about $5 \%$, and this shows that the results of the numerical simulations are reliable. 

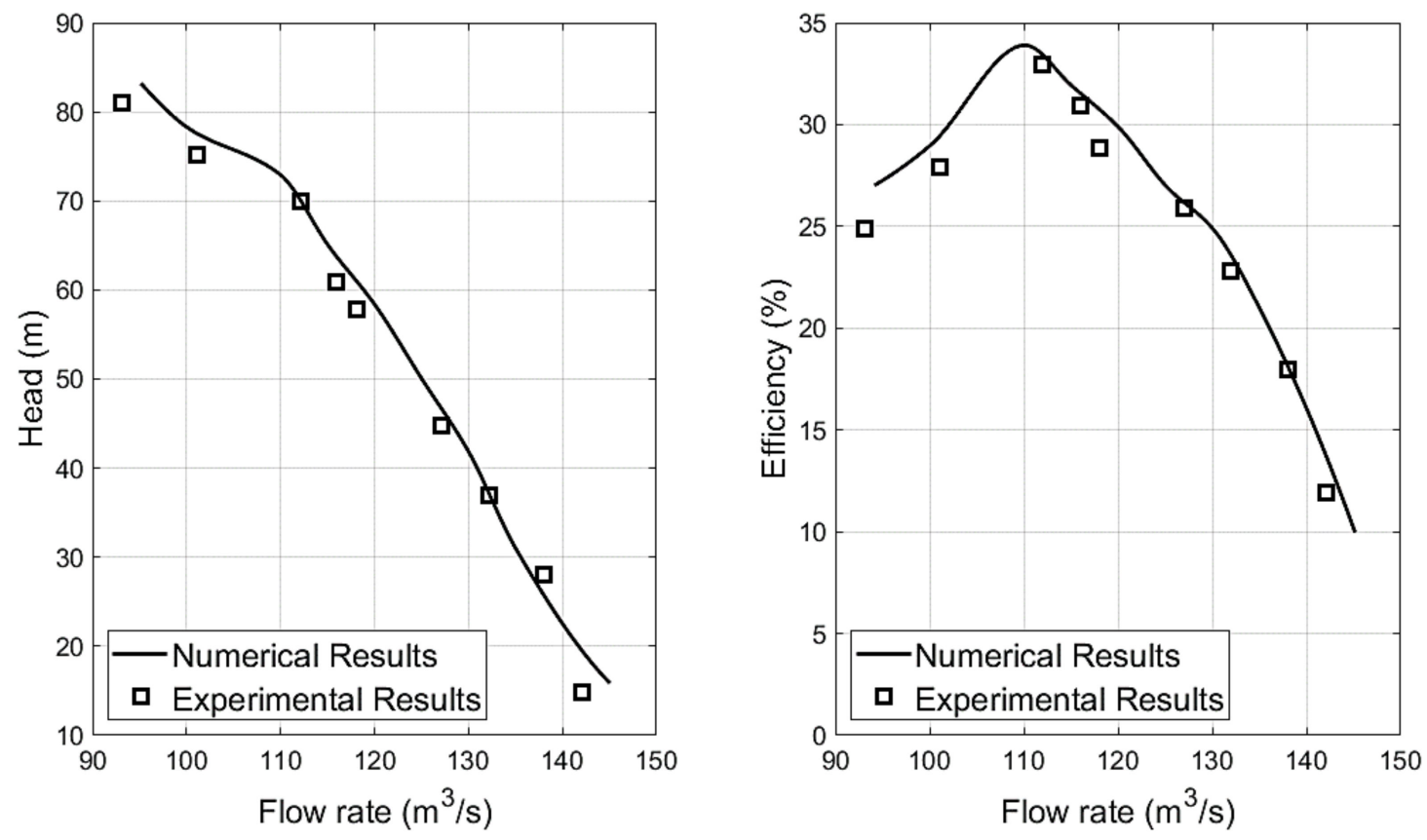

Figure 3. Comparison of experimental data and numerical results.

\subsection{Mesh Generation and Mesh Independence Validation}

In consideration that the turbulence distribution characteristics are similar in each stage of the pressurized unit, and for the convenience of saving computing resources, a three-stage pressurized unit model is selected for the numerical research in the next.

The three-dimensional models of rotating impeller, static impeller, suction chamber, and extrusion chamber of the multiphase pump were established, to obtain the threedimensional flow model of the flow field in the calculation domain of the multiphase pump, as shown in Figure 4. Figure 5 is the meridian parameters of the impeller and diffuser. Figure 6 is the physical model of the rotating impeller.

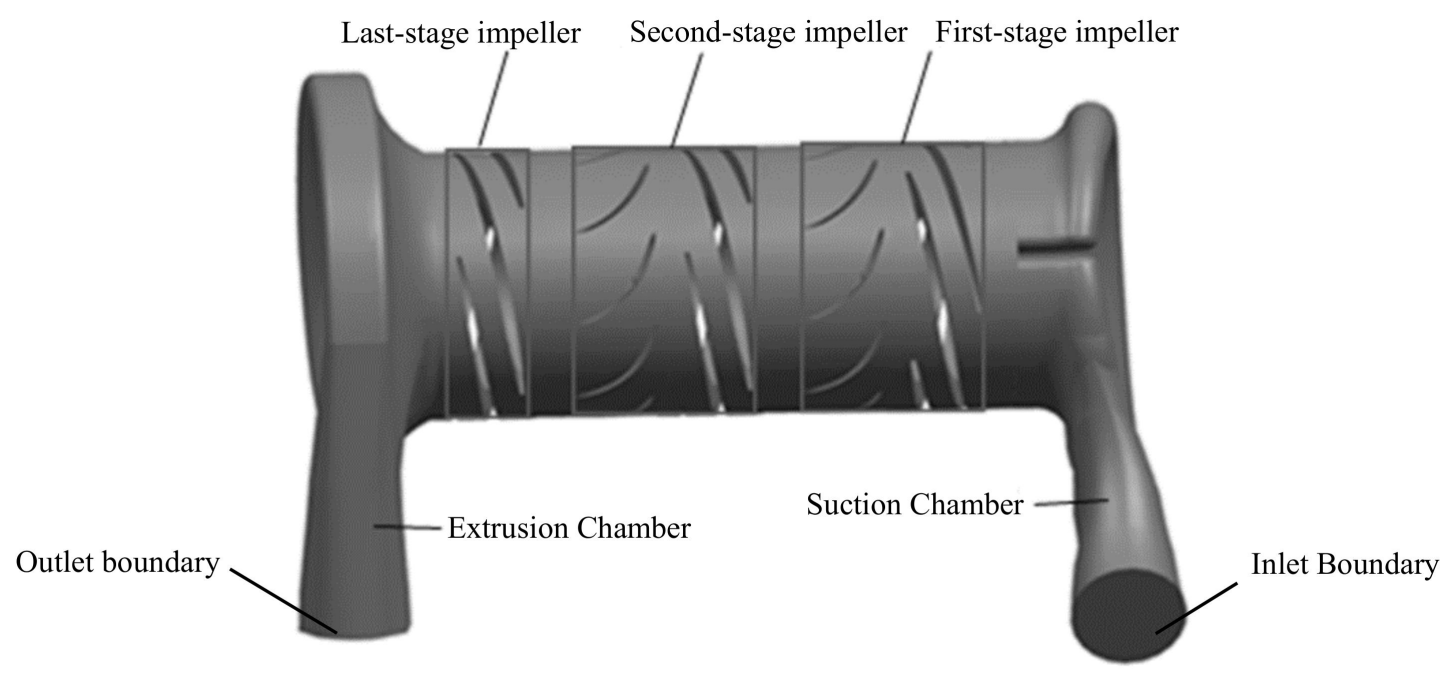

Figure 4. The three-dimensional model of the multiphase pump. 


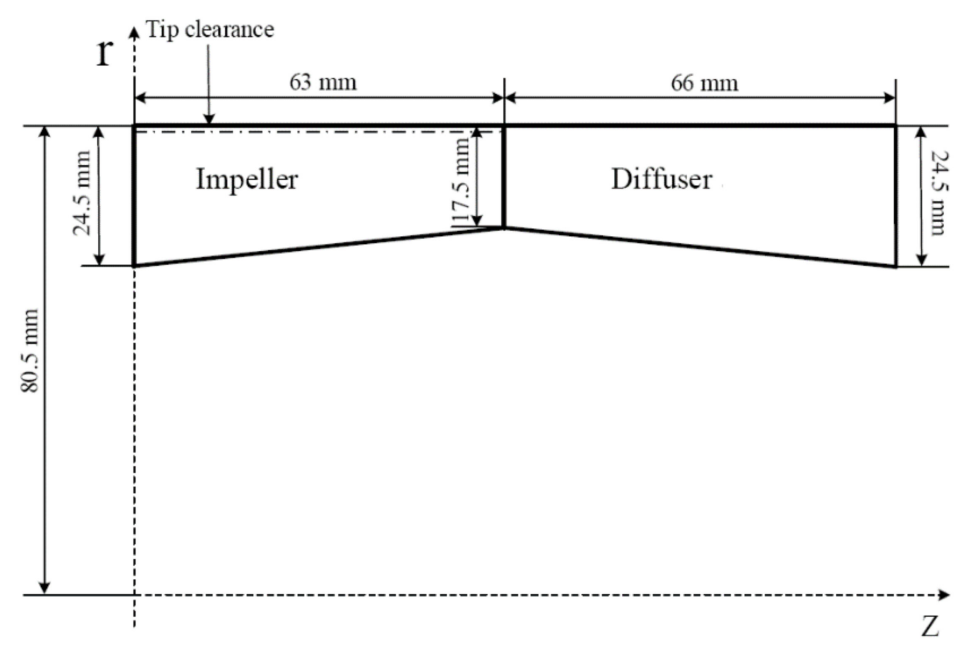

Figure 5. Meridian parameters of the impeller and diffuser.

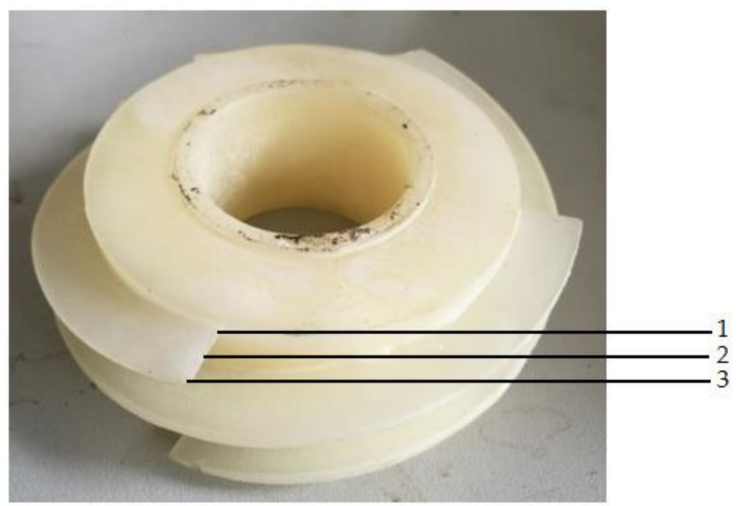

Figure 6. Physical model of the rotating impeller. 1. Hub, 2. 0.5 Span, 3. Shroud.

The models of the suction chamber, extrusion chamber, rotating impeller, and static impeller were meshed, respectively. The internal flow flied was simpler in the suction chamber and the extrusion chamber than that in the pressurized stage units, because the suction chamber and the extrusion chamber of the multiphase pump were used to provide and eliminate the velocity circulation, respectively. Therefore, unstructured tetrahedral meshes with more adaptability were used in the suction chamber and the extrusion chamber, as shown in Figure 7.

Since the pressurized stage units of the multiphase pump were focused on in this paper, the hexahedral structural meshes were used for rotating and static impellers of the multiphase pump, as shown in Figure 8.

In the numerical simulation of the multiphase pump, the quality and the number of cells can affect the accuracy and the computational speed directly. In order to reduce the effect of the number of cells on the calculation results, different mesh sizes were set for all parts of the multiphase pump under the same conditions. The changes of efficiency and water head with the number of cells under design conditions were shown in Figure 9. As shown, when the number of cells was increased from 5.247 to 6.150 million, the water head and efficiency were only increased by $0.06 \%$ and $0.03 \%$, respectively, which could meet the meshing independence requirements. If the number of cells was increased continuously, the time of calculation would be increased sharply, but there would be little effect on the calculation results. Therefore, based on the meshing independence verification results, 5.247 million cells were used for the simulation in the flow domain of the multiphase pump. 


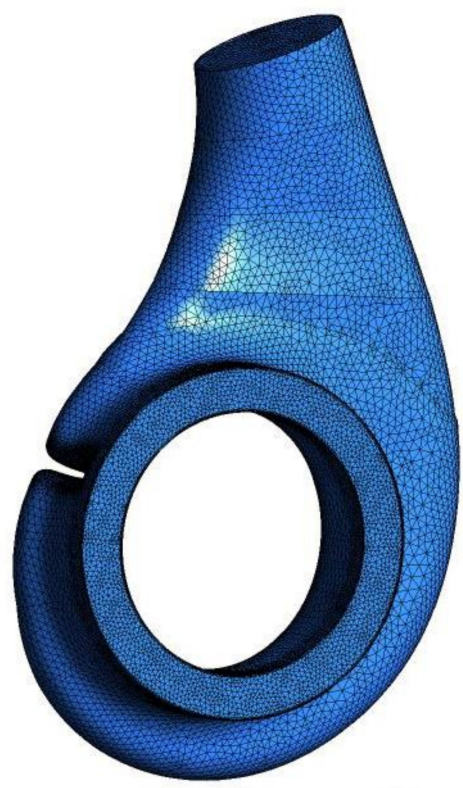

Suction chamber

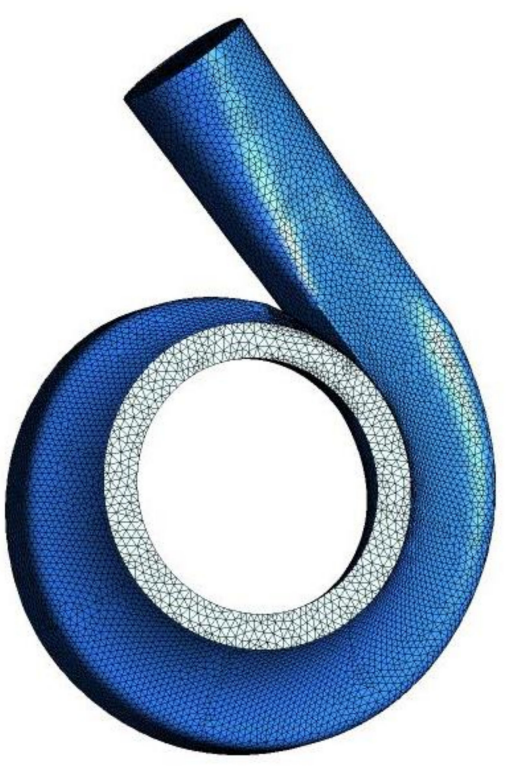

Extrusion chamber

Figure 7. Tetrahedral meshes of the suction chamber and extrusion chamber.

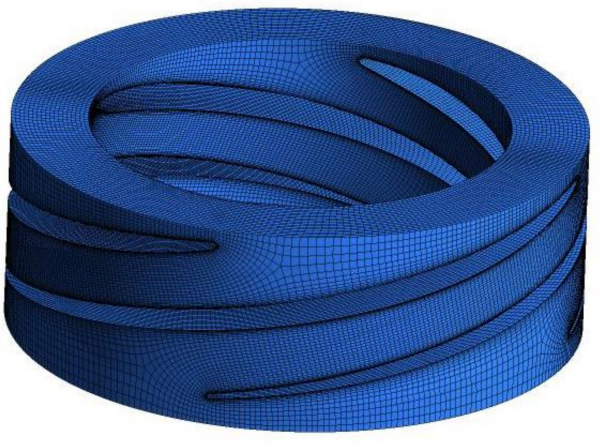

Rotating impeller

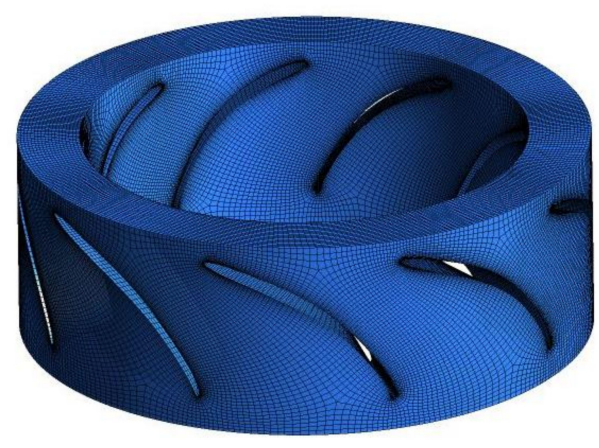

Static impeller

Figure 8. Hexahedral meshes of the pressurized unit.

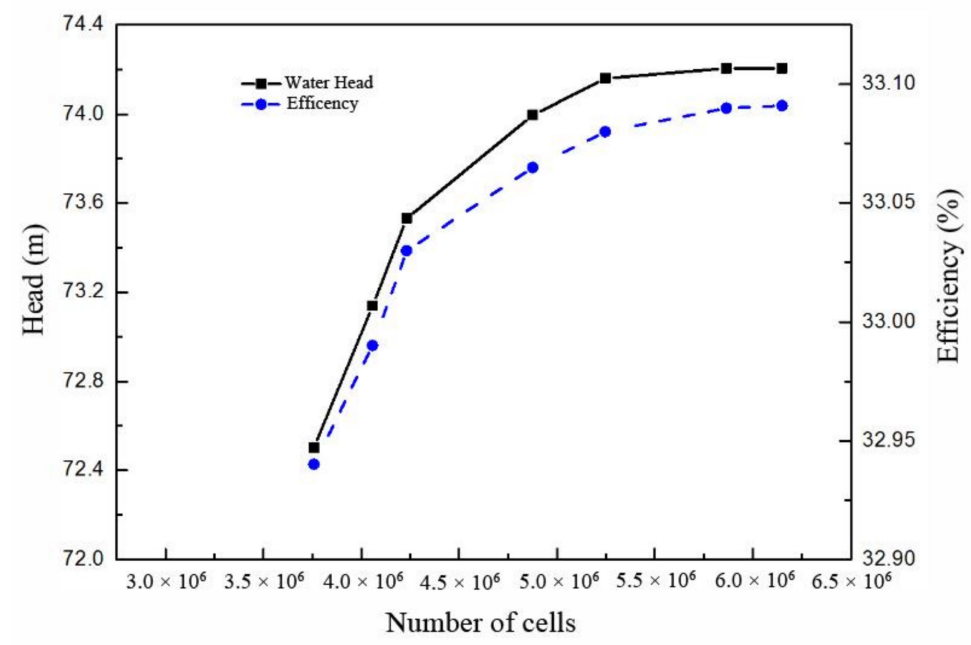

Figure 9. The grid independence verification. 


\section{Analysis}

4.1. Effects of the Flow Rate on Turbulence Dissipation Rate Distribution at Different Heights of Blade

4.1.1. Effect of the Flow Rate on the Turbulence Dissipation Distribution Rate at the Hub of First-Stage Rotating Impeller

The turbulence dissipation rate distribution of the pressure surface and suction surface of the blade at the hub of the first-stage rotating impeller under different flow rates is shown in Figure 10. It could be seen that a large turbulence dissipation rate occurred at the inlet of the pressure surface of the rotating impeller and increased with the increase in flow rate, while a very small turbulence dissipation rate occurred from the inlet to the middle of the outlet of the static impeller blade at different flow rates, the turbulence dissipation rate on the suction surface had the same trend with that on the pressure surface of the rotating impeller and the larger turbulence dissipation rate was mainly located at the inlet and outlet of the rotating impeller.

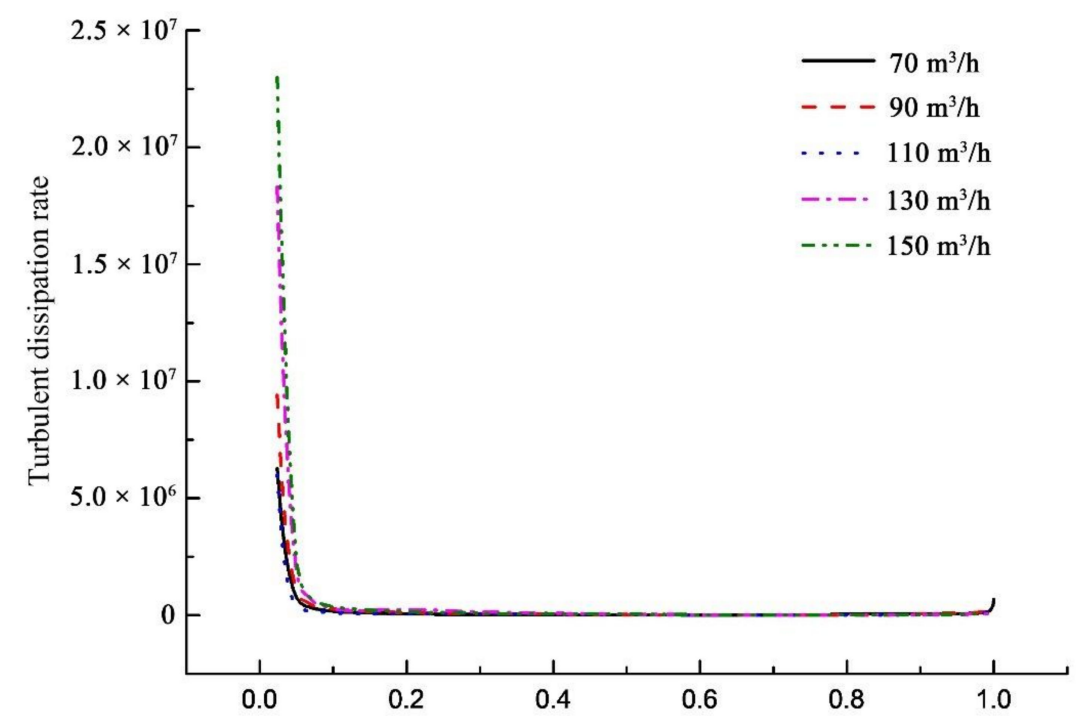

Relative position along the streamline on the pressure surface at the hub

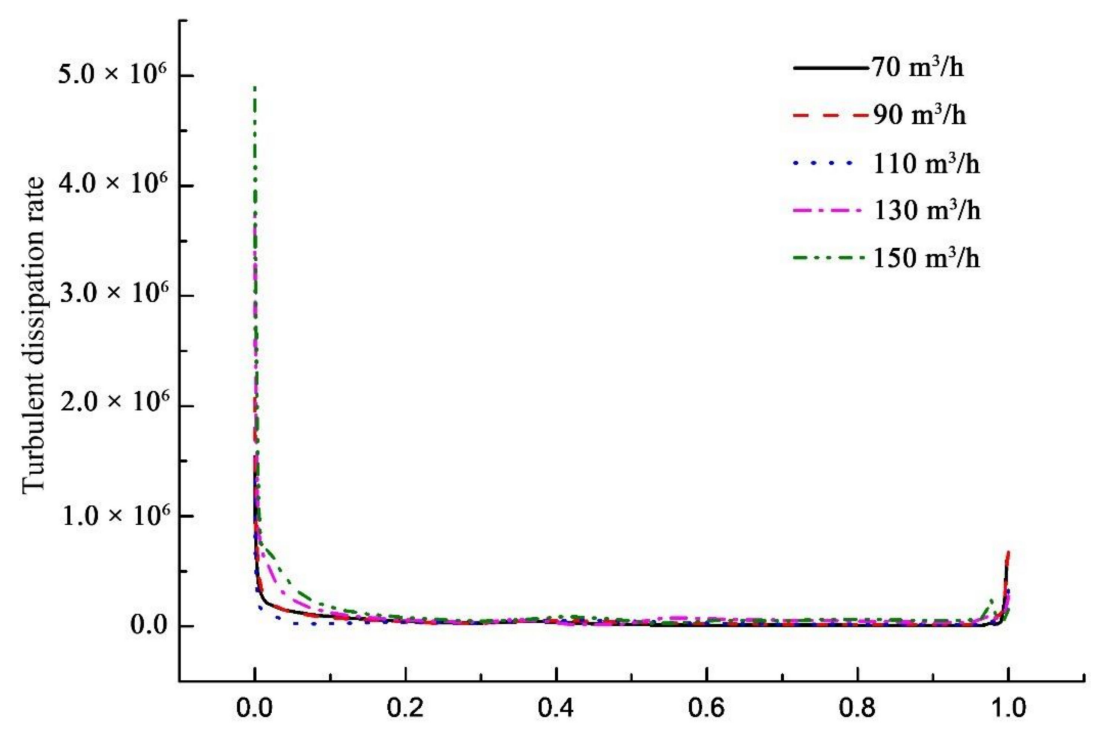

Relative position along the streamline on the pressure surface at the hub

Figure 10. The turbulence dissipation rate distribution pattern of the pressure surface and the suction surface of the first-stage impeller blade at the hub with different flow rates. 
4.1.2. Effect of the Flow Rate on the Turbulence Dissipation Rate Distribution at 0.5 Times of the Blade Height on the First-Stage Rotating Impeller

The flow rate distribution diagram at 0.5 times the blade height on the multiphase pump is shown in Figure 11. The turbulence dissipation rate distribution on the pressure surface and suction surface of the blade on the first-stage rotating impeller at 0.5 times the blade height and at different flow rates is shown in Figure 12. It could be seen from both figures that a large turbulence dissipation rate occurred at the inlet of the pressure surface of the rotating impeller and increased with the increase of the flow rate in the multiphase pump, while a very small and uniform turbulence dissipation rate occurred from the inlet to the middle of the outlet of the static impeller blade at different flow rates, the turbulence dissipation rate on the suction surface had the same trend with that on the pressure surface of the rotating impeller and the larger turbulence dissipation rate was mainly located at the inlet and outlet of the rotating impeller. However, the value of the turbulence dissipation rate on the suction surface of the rotating impeller blade was greater than that on the pressure surface of the rotating impeller blade at the same position, because the area with large flow rate changes was mainly distributed on the suction surface of the rotating impeller blade, which indicated that the flow on the suction surface was not as stable as that on the pressure surface of the rotating impeller blade.

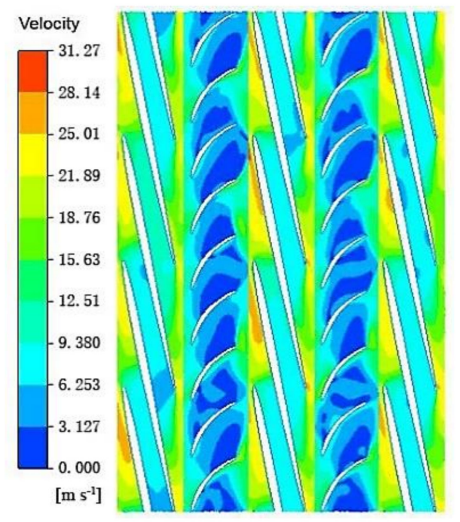

$70 \mathrm{~m}^{3} / \mathrm{h}$

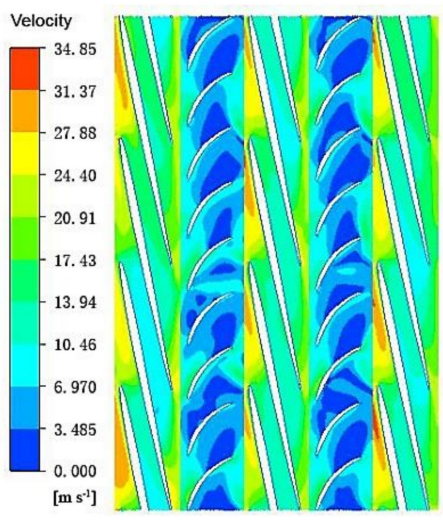

$110 \mathrm{~m}^{3} / \mathrm{h}$

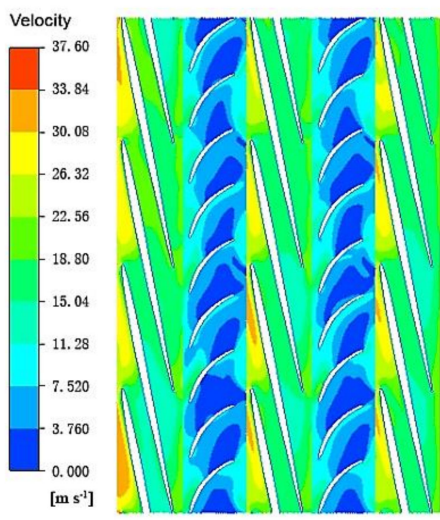

$150 \mathrm{~m}^{3} / \mathrm{h}$

Figure 11. Contour of the velocity at 0.5 span.

4.1.3. Effect of the Flow Rate on the Turbulence Dissipation Rate Distribution Law at the Rim of Blade on the First-Stage Rotating Impeller

The flow rate distribution diagram at 0.8 times the blade height of the multiphase pump is shown in Figure 13 and the turbulence dissipation rate distributions on the pressure surface and suction surface at the rim of the blade on the first-stage rotating impeller under different flow rates is shown in Figure 14. It could be seen from Figure 14 that a large turbulence dissipation rate occurred at the inlet of the pressure surface of the rotating impeller and increased with the increase in flow rate in the multiphase pump, while a very small turbulence dissipation rate occurred from the inlet to the middle of the outlet of the static impeller blade at different flow rates, the turbulence dissipation rate on the suction surface had the same trend with that on the pressure surface of the rotating impeller and the larger turbulence dissipation rate was mainly located at the inlet and outlet of the rotating impeller. It could be seen from Figures 13 and 14 that there was an area with a local small flow rate on the suction surface of blade on the rotating impeller, resulting in uneven flow rate distribution and turbulent flow. Therefore, there were some obvious fluctuations in the turbulence dissipation rate on the suction surface of the rotating impeller. 


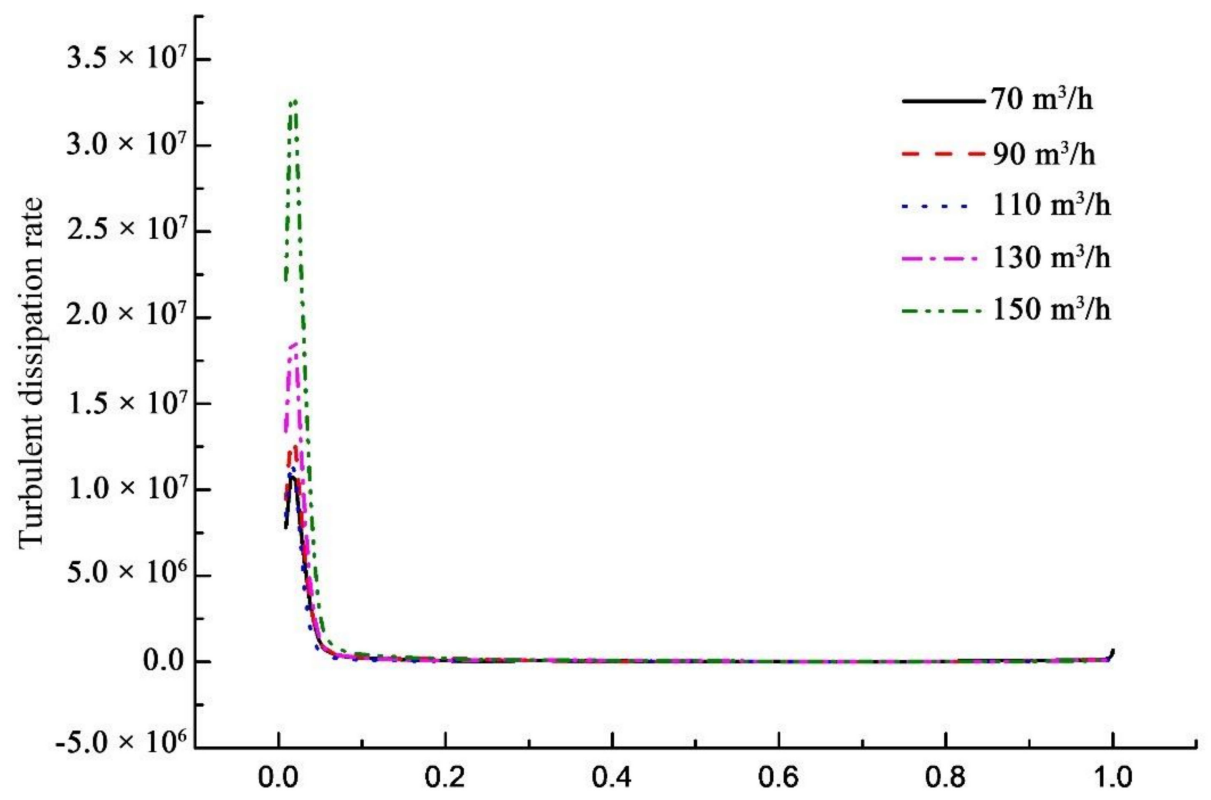

Relative position along the streamline on the pressure surface at 0.5 span

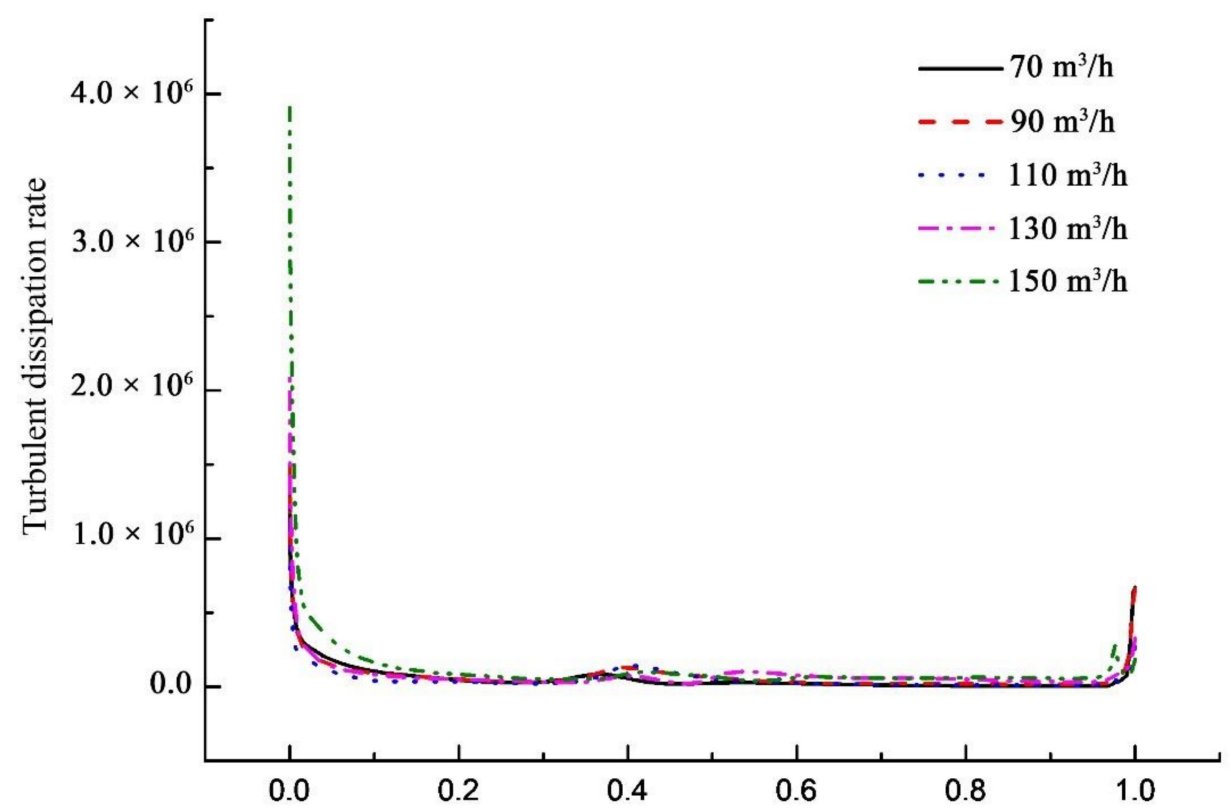

Relative position along the streamline on the suction surface at 0.5 span

Figure 12. The turbulence dissipation rate distribution pattern of the pressure surface and the suction surface of the first-stage impeller blade at the 0.5 span under different flow rates.

4.2. Effect of the Flow Rate on the Turbulence Dissipation Rate on Different Radial Sections of the First-Stage Rotating Impeller

In this paper, the flow rate on each-stage pressurized unit of the multiphase pump was calculated. However, because that the first-stage rotating impeller of the multiphase pump was more sensitive to the flow rate changes, it was selected for the research on the turbulence dissipation rate. 


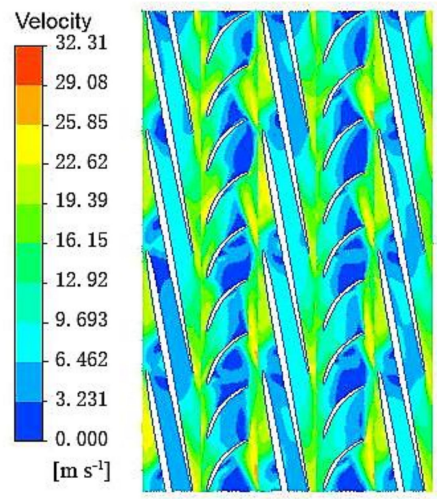

$70 \mathrm{~m}^{3} / \mathrm{h}$

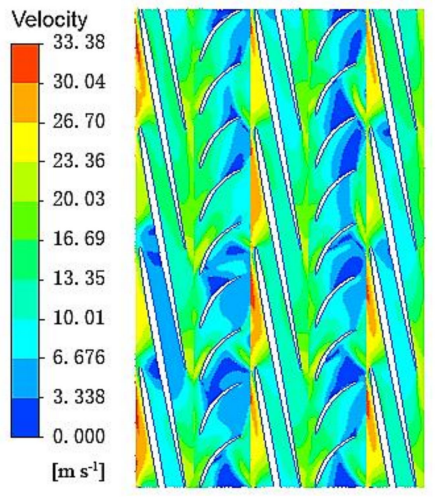

$110 \mathrm{~m}^{3} / \mathrm{h}$

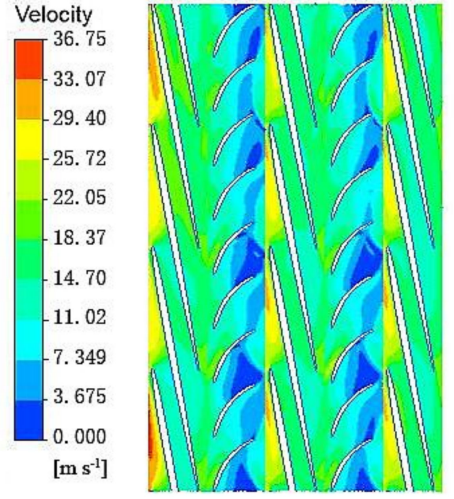

$150 \mathrm{~m}^{3} / \mathrm{h}$

Figure 13. Contour of the velocity at 0.8 span.

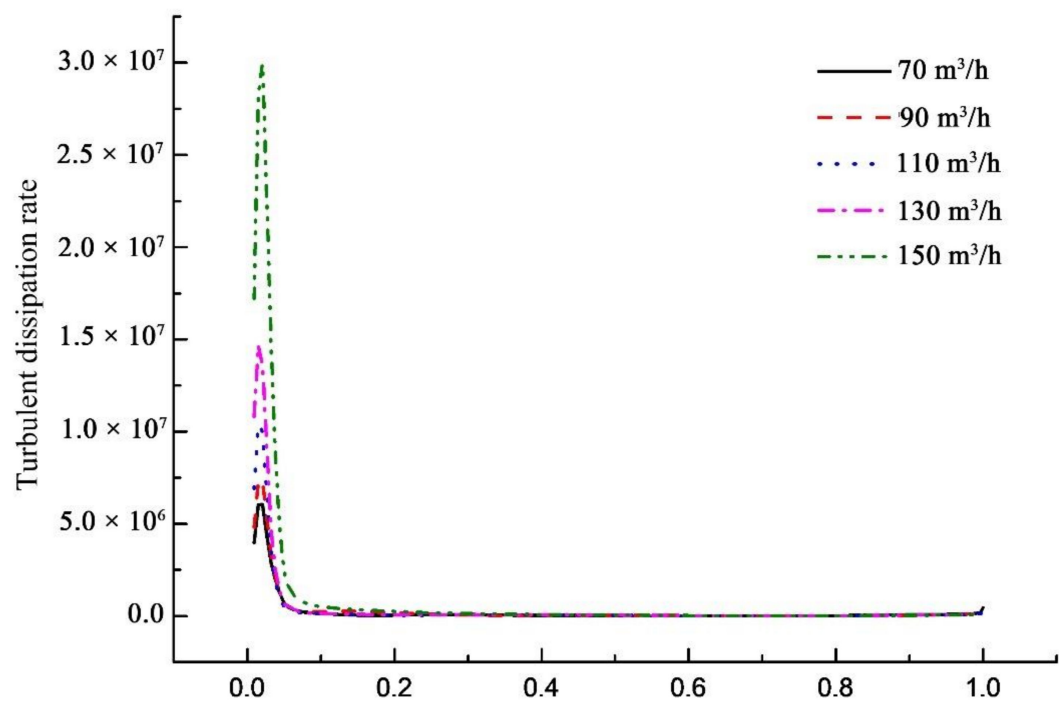

Relative position along the streamline on the pressure surface at 0.8 span

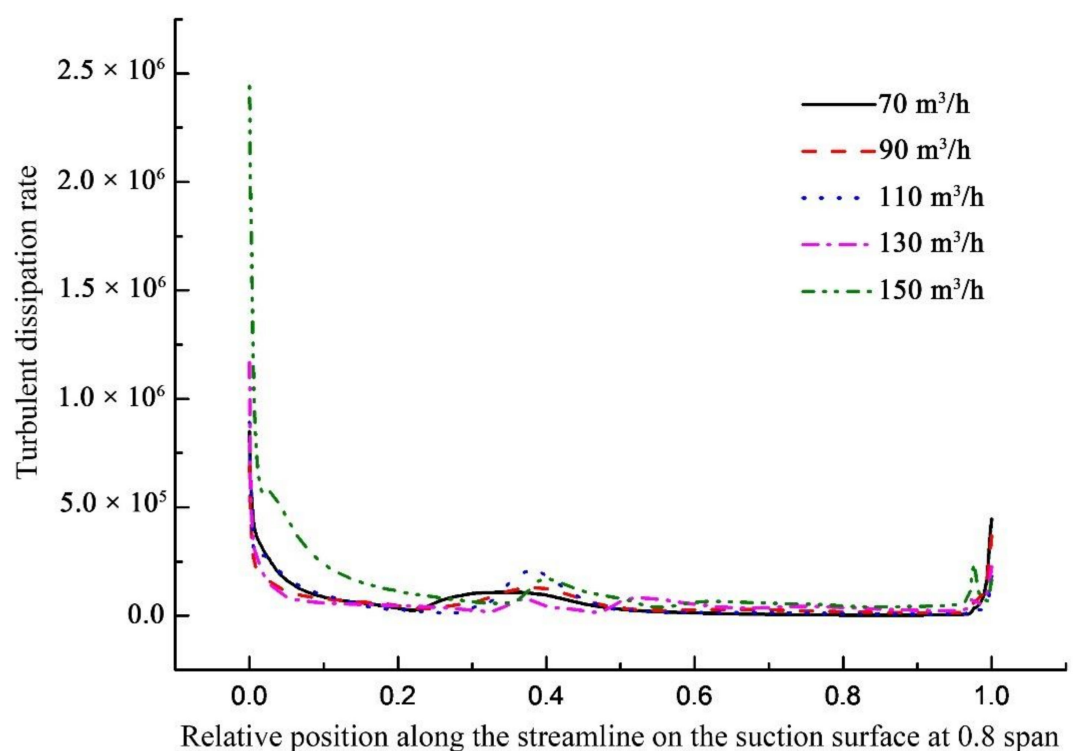

Figure 14. The turbulence dissipation rate distribution pattern of the pressure surface and the suction surface of the first-stage impeller blade at the shroud under different flow rates. 
4.2.1. Effect of the Flow Rate on the Turbulence Dissipation Rate from the Hub to the Rim on the Inlet Section of the First-Stage Rotating Impeller

The turbulence dissipation rate from the hub to the rim on the inlet section of the first-stage rotating impeller of the multiphase pump at different flow rates is shown in Figure 15. It could be seen that the turbulence dissipation rate was increased gradually from the hub to the rim on the inlet section of the first-stage rotating impeller of the multiphase pump, its value at a large flow rate was greater than that at a small flow rate generally from the hub to 0.5 times the blade height, while its value at a small flow rate was greater than that at a large flow rate generally from 0.5 times the blade height to the rim, which indicated that there was a more turbulent flow near the hub at a large flow rate and near the rim at a small flow rate on the inlet section of the first-stage rotating impeller of the multiphase pump.

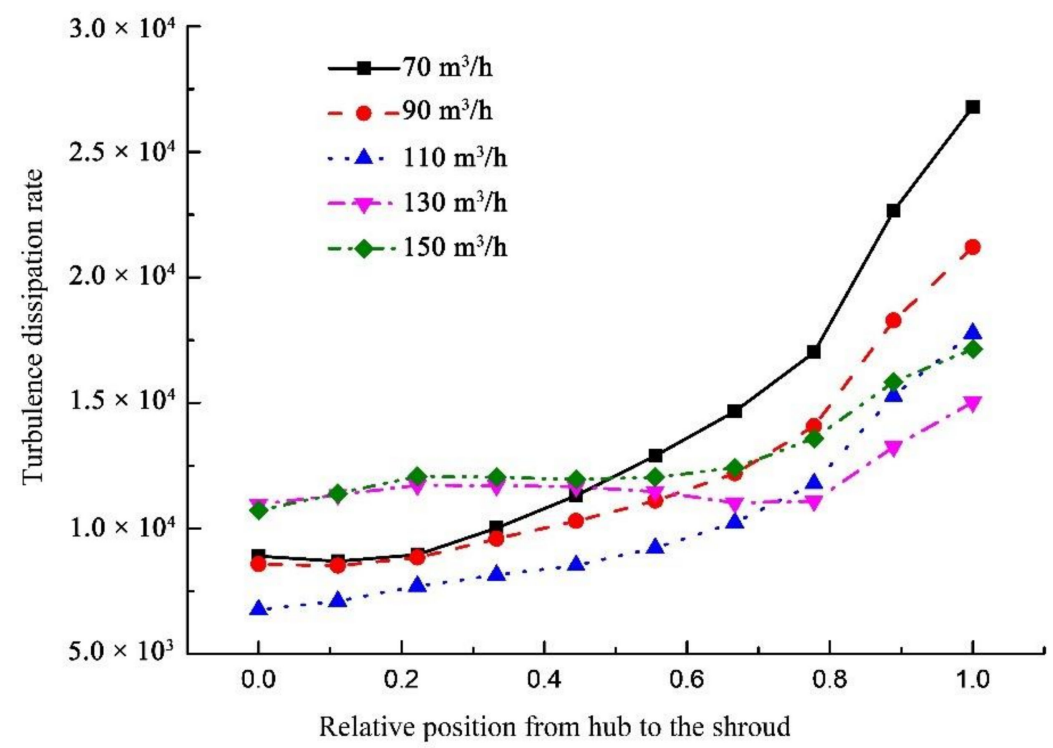

Figure 15. The variation of turbulence dissipation rate from the hub to the shroud of the first impeller inlet section under different flow rates.

4.2.2. Effect of the Flow Rate on the Turbulence Dissipation Rate from the Hub to the Rim on the Middle Section of the First-Stage Rotating Impeller

The turbulence dissipation rate from the hub to the rim on the middle section of the first-stage rotating impeller of the multiphase pump at different flow rates is shown in Figure 16. It could be seen that the turbulence dissipation rate was decreased firstly and then increased from the hub to the rim on the middle section of the first-stage rotating impeller of the multiphase pump, its value was fluctuated greatly at a large flow rate and slightly at a small flow rate, there were two turning points near the 0.2 times and 0.8 times the blade height, its value at the rim was greater than that at the hub, and its value at the large flow rate was obviously greater than that at a small flow rate from the hub to the rim, which indicated there was a more turbulent flow at a large flow rate and a relatively smooth flow at a small flow rate on the middle section of the first-stage rotating impeller of the multiphase pump. 


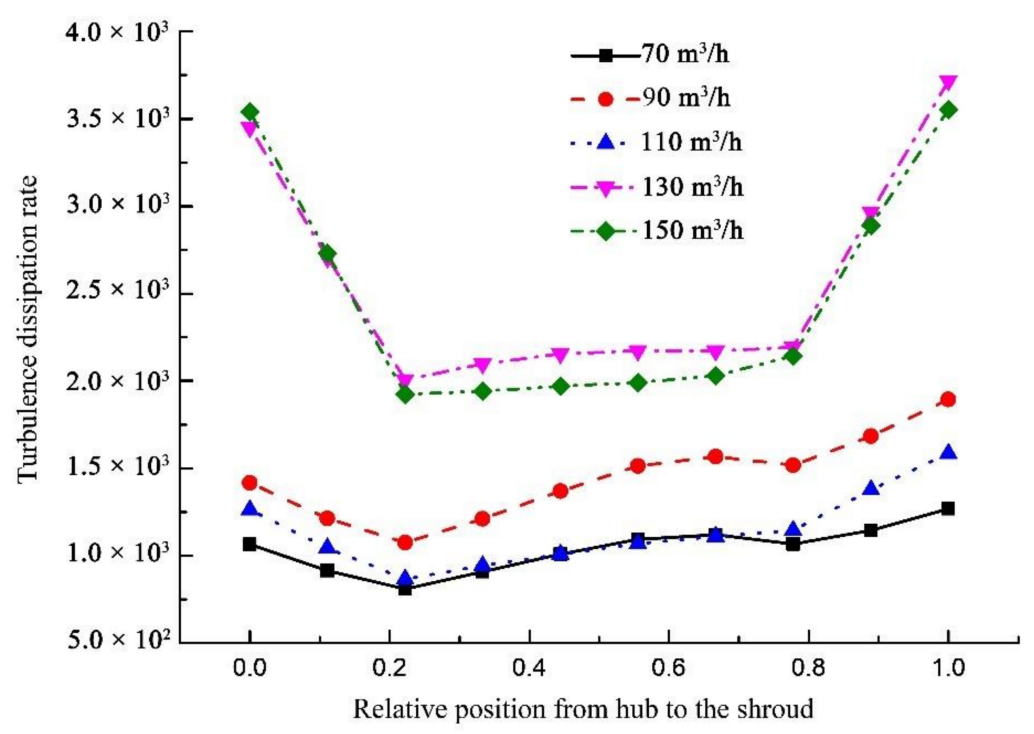

Figure 16. The variation of turbulence dissipation rate from the hub to the shroud of the first impeller middle section under different flow rates.

4.2.3. Effect of the Flow Rate on the Turbulence Dissipation Rate from Hub to Rim on the Outlet Section of the First-Stage Rotating Impeller

The turbulence dissipation rate from the hub to the rim on the outlet section of the first-stage rotating impeller of the multiphase pump at different flow rates is shown in Figure 17. It could be seen that the turbulence dissipation rate was decreased firstly and then increased from the hub to the rim on the outlet section of the first-stage rotating impeller of the multiphase pump, its value at the hub was greater than that at the rim, and its value at a small flow rate was greater than that at a large flow rate generally, which indicated that the flow rate at a small flow rate was more turbulent than that at arge flow rate, and the flow rate at the hub was more turbulent than that at the rim on the outlet section of the first-stage rotating impeller of the multiphase pump. There was the maximum turbulence dissipation rate at the flow rate of $90 \mathrm{~m}^{3} / \mathrm{h}$, which indicated that there was the largest energy loss from the hub to the rim on the outlet section of the rotating impeller at this flow rate.

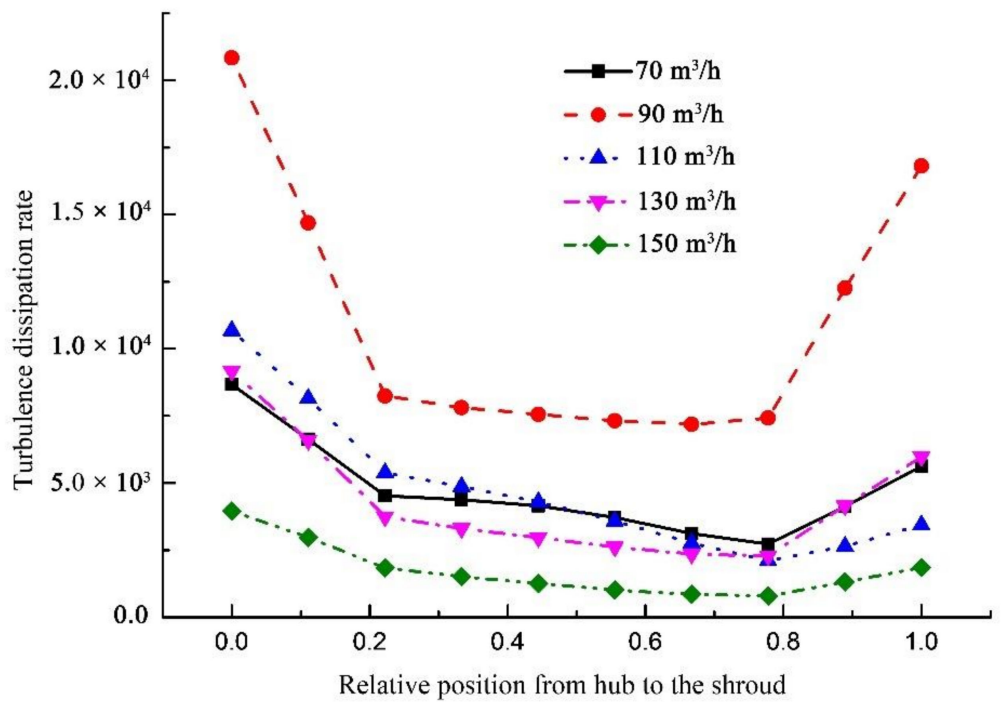

Figure 17. The variation of turbulence dissipation rate from the hub to the shroud of the first impeller outlet section of the multiphase pump under different flow rates. 
4.3. Effects of the Flow Rate on the Circumferential Turbulence Dissipation Rate at Different Blade Heights on the Outlet Section of the First-Stage Rotating Impeller

It could be seen from Figure 17 that the turbulence dissipation rate was fluctuated greatly with the changes in the flow rate on the outlet section of the first-stage rotating impeller, which indicated that there was relatively turbulent flow and relatively large energy loss here. Therefore, the outlet section of the first-stage rotating impeller was mainly selected for research and analysis of the effect of the flow rate on the circumferential turbulence dissipation rate at different blade heights on the outlet section of the firststage impeller.

4.3.1. Effect of the Flow Rate on the Circumferential Turbulence Dissipation Rate at the Hub on the Outlet Section of the First-Stage Impeller

The circumferential turbulence dissipation rate at the hub on the outlet section of the first-stage rotating impeller at different flow rates is shown in Figure 18. It could be seen that the turbulence dissipation rate was unevenly distributed in the circumferential direction and the area with larger turbulence dissipation rate was biased to one side at the hub on the outlet section of the first-stage rotating impeller of the multiphase pump, and its value was up to the maximum at the flow rate of $90 \mathrm{~m}^{3} / \mathrm{h}$, and then decreased at the flow rate of $110,130,70$, and $150 \mathrm{~m}^{3} / \mathrm{h}$ successively and these values could directly reflect the turbulence dissipation losses, which indicated that when there were the maximum and the minimum turbulence dissipation losses at the flow rate of 90 and $150 \mathrm{~m}^{3} / \mathrm{h}$ at the hub on the outlet section of the first-stage rotating impeller of the multiphase pump.

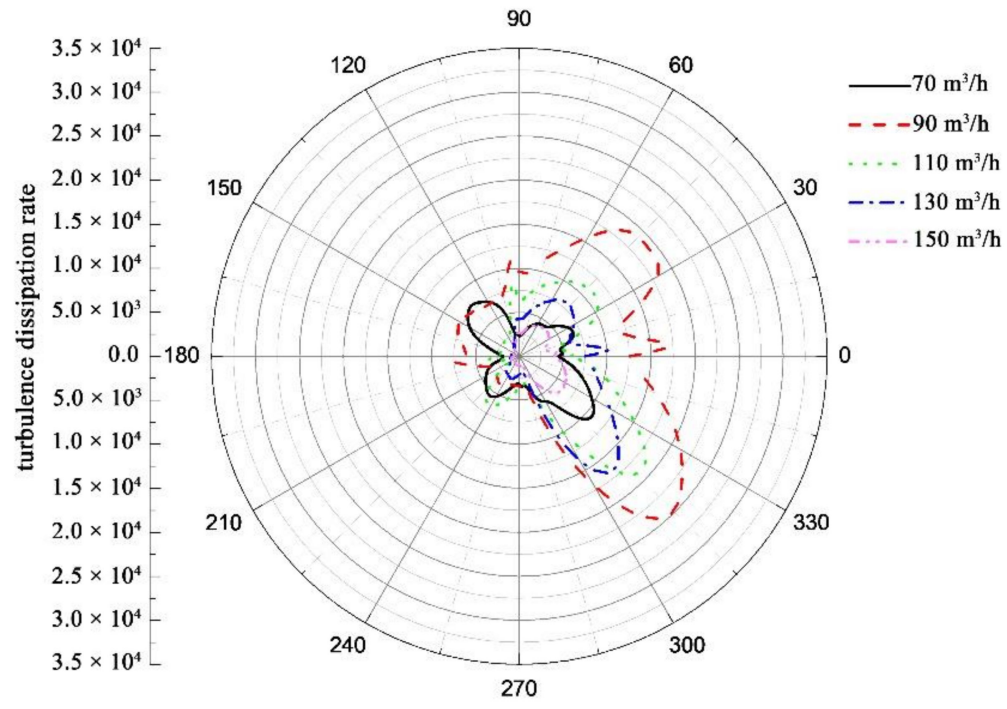

Figure 18. The variation of the circumferential turbulence dissipation rate at the outlet section hub within the first impeller under different flow rates.

4.3.2. Effect of the Flow Rate on the Circumferential Turbulence Dissipation Rate at 0.5 Times of the Blade Height on the Outlet Section of the First-Stage Rotating Impeller

The circumferential turbulence dissipation rate at 0.5 times of the blade height on the outlet section of the first-stage rotating impeller at different flow rates is shown in Figure 19. It could be seen that the turbulence dissipation rate was unevenly distributed in the circumferential direction at 0.5 times the blade height on the outlet section of the first-stage rotating impeller of the multiphase pump, and there were four turning points that were the same as the number of impeller blades on the turbulence dissipation rate distribution at the flow rate of $90 \mathrm{~m}^{3} / \mathrm{h}$, indicating three larger values and one smaller value. 


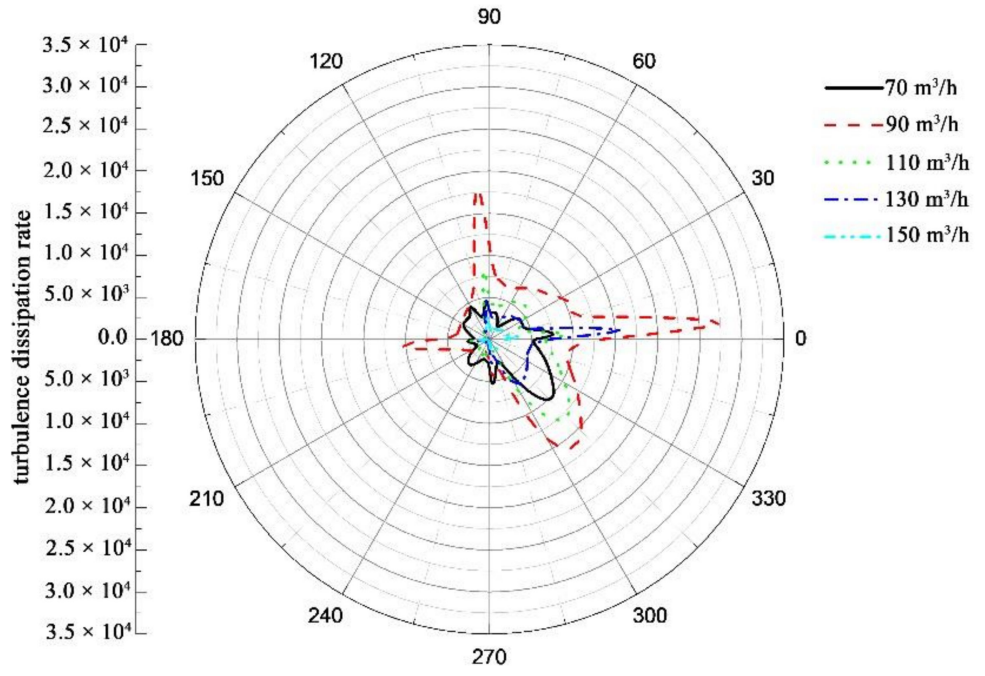

Figure 19. The variation of the circumferential turbulence dissipation rate at the outlet section 0.5 span within the first impeller under different flow rates.

4.3.3. Effect of the Flow Rate on the Circumferential Turbulence Dissipation Rate at the Rim on the Outlet Section of the First-Stage Rotating Impeller

The circumferential turbulence dissipation rate at the rim on the outlet section of the first-stage rotating impeller at different flow rates is shown in Figure 20. It could be seen that the turbulence dissipation was unevenly distributed in the circumferential direction at the rim on the outlet section of the first-stage rotating impeller of the multiphase pump, especially there was an obvious maximum value at the flow rate of $90 \mathrm{~m}^{3} / \mathrm{h}$, and the turbulence dissipation rate at this flow rate was obviously greater than those at other flow rates. In the case of the $90 \mathrm{~m}^{3} / \mathrm{h}$ flow rate, the operational point was just deviating from the optimal point, the flow field became more turbulent. When the flow rate is $70 \mathrm{~m}^{3} / \mathrm{s}$, the velocity decreased with the decrease of flow rate, the turbulence intensity decreased, also the turbulence dissipation rate.

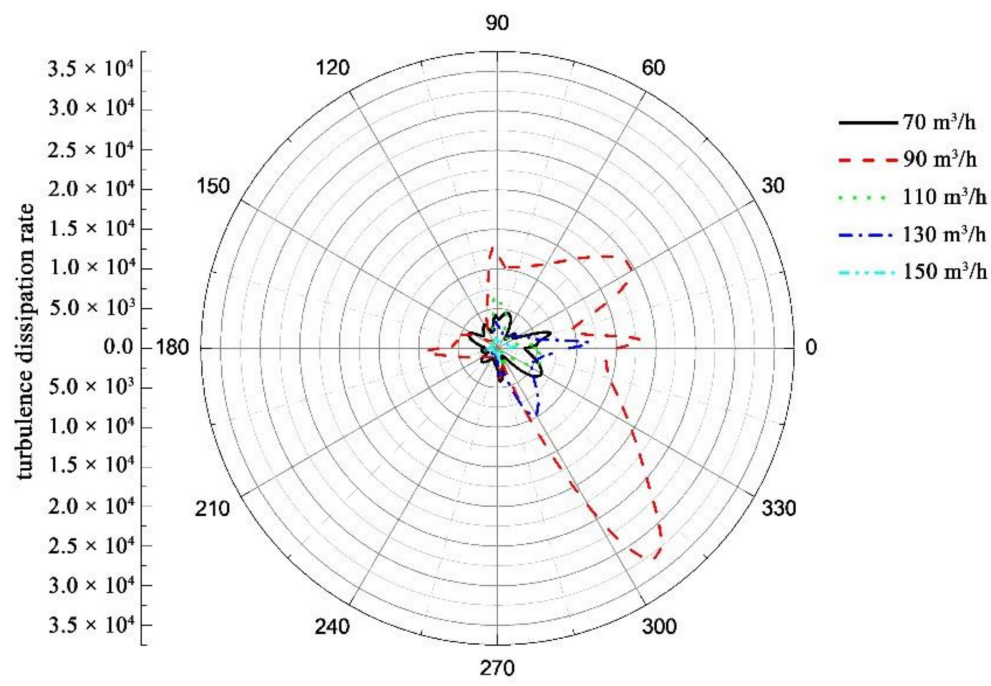

Figure 20. The variation rule of the circumferential turbulence dissipation rate at the outlet section shroud within the first impeller under different flow rates. 


\subsection{Effect of the Flow Rate on the Turbulence Dissipation Rate on the Axial Section of the Booster Unit}

The axial flow rate distributions at different blade heights in the compression stage of the multiphase pump are shown in Figures 21-23 and the turbulence dissipation rate from the inlet of the first-stage rotating impeller to the outlet of the last-stage rotating impeller at different flow rates is shown in Figure 24. It could be seen from Figures 11-24 that the axial vortices were mainly distributed in the static impeller of the multiphase pump, the flow rate was relatively turbulent in the static impeller and relatively uniform in the rotating impeller of the multiphase pump, so the overall turbulence dissipation rate in the static impeller was greater than that in the rotating impeller. At a small flow rate, there was a flow separation in the axial direction at the inlet of the rotating impeller and the vortices were filled in the entire channel of the static impeller. As the flow rate was increased, the flow separation disappeared in the rotating impeller and the vortices were decreased in the static impeller gradually, so the turbulence dissipation rate was reduced gradually. It could also be seen from Figure 21 that the turbulence dissipation rate was relatively large at the inlet and outlet but relatively small at the middle of the rotating impeller and the static impeller, which indicated that the turbulence dissipation rate was increased due to the nonuniform flow at the inlet and outlet of the rotating and static impellers.

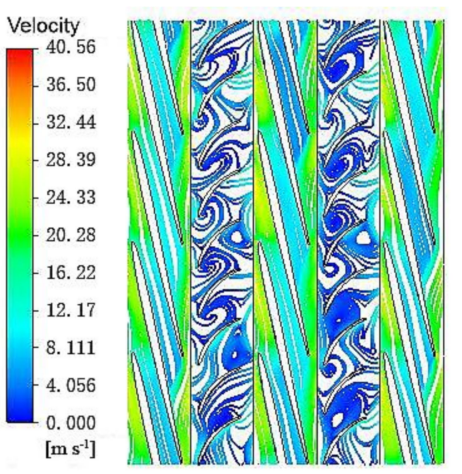

$70 \mathrm{~m}^{3} / \mathrm{h}$

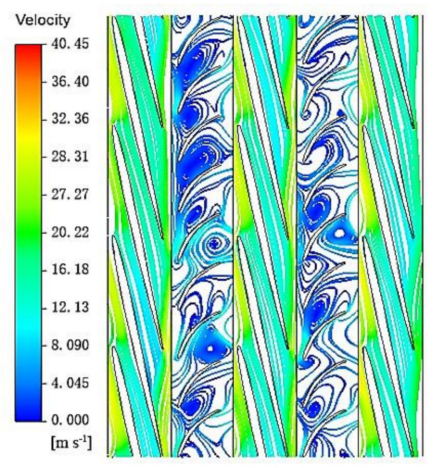

$110 \mathrm{~m}^{3} / \mathrm{h}$

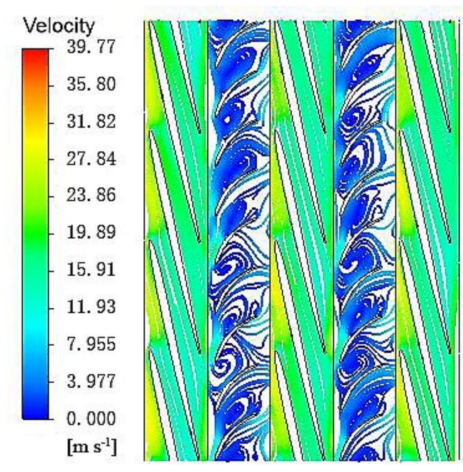

$150 \mathrm{~m}^{3} / \mathrm{h}$

Figure 21. Axial streamline distribution at 0.2 span of the compressor stage.

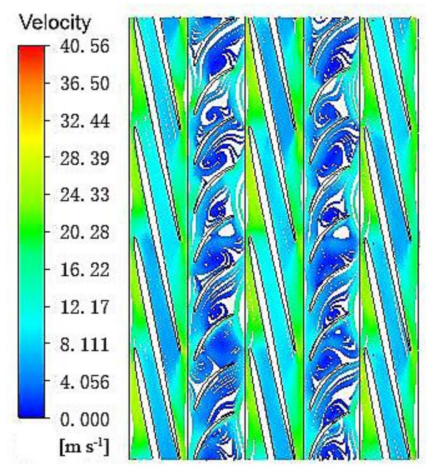

$70 \mathrm{~m}^{3} / \mathrm{h}$

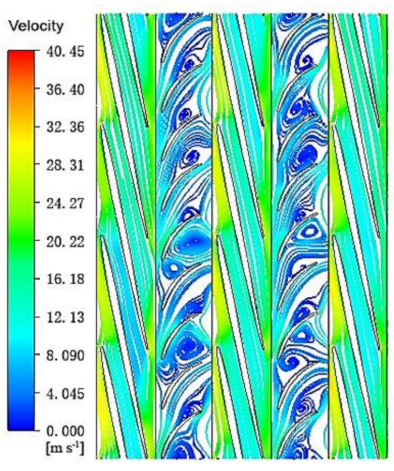

$110 \mathrm{~m}^{3} / \mathrm{h}$

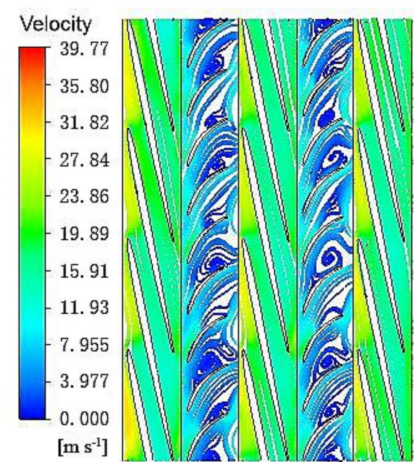

$150 \mathrm{~m}^{3} / \mathrm{h}$

Figure 22. Axial streamline distribution at 0.5 span of the compressor stage. 


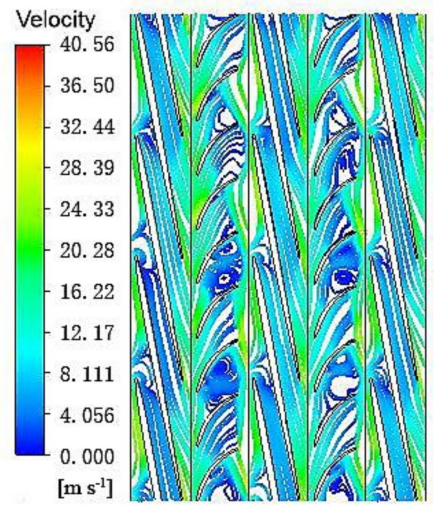

$70 \mathrm{~m}^{3} / \mathrm{h}$

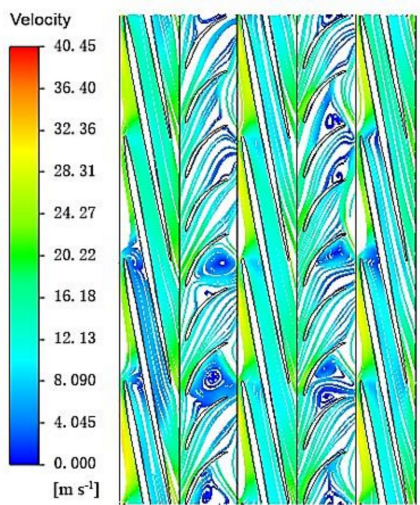

$110 \mathrm{~m}^{3} / \mathrm{h}$

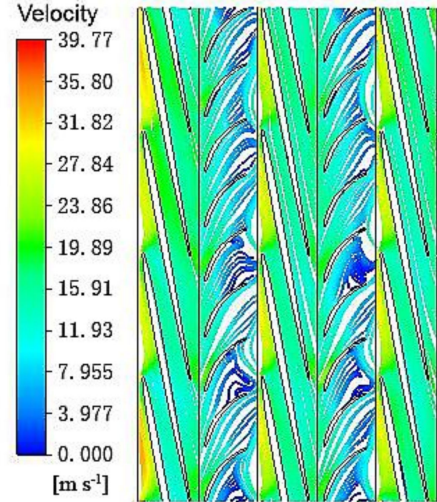

$150 \mathrm{~m}^{3} / \mathrm{h}$

Figure 23. Axial streamline distribution at 0.8 span of the compressor stage.

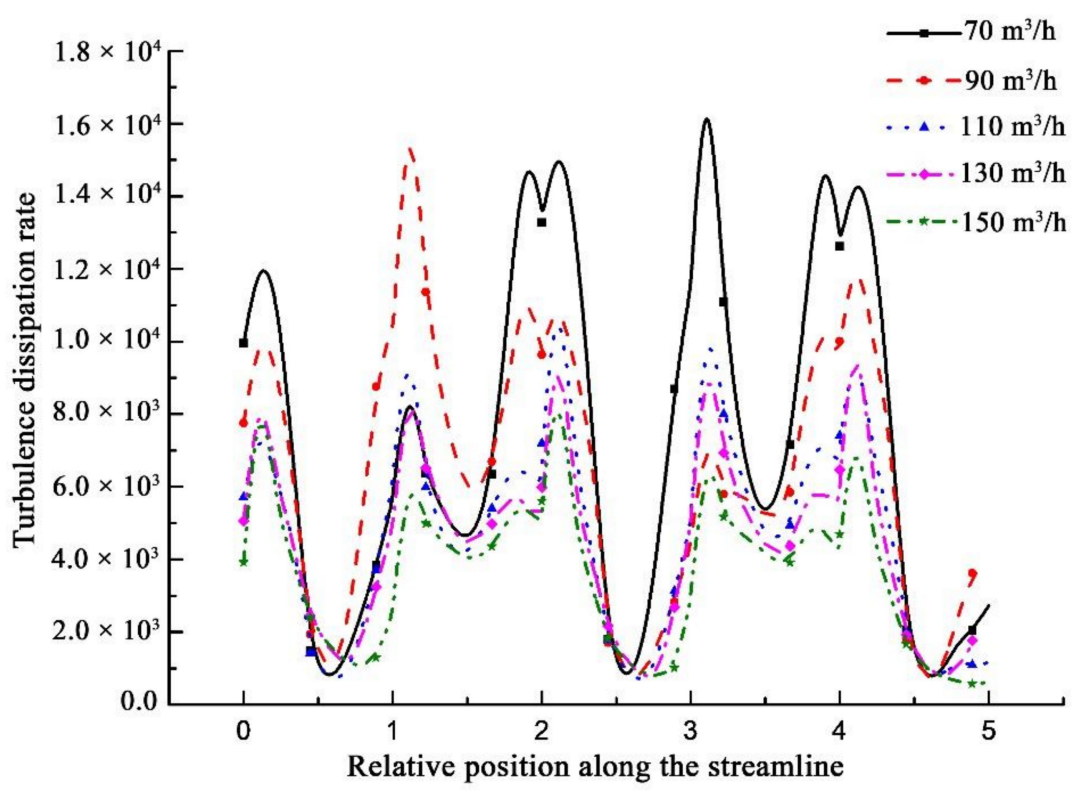

Figure 24. The variation of turbulence dissipation rate from the inlet of the first-stage rotating impeller to the outlet of the last-stage rotating impeller at different flow rates.

\section{Conclusions}

(1) At different flow rate, the areas with greater turbulence dissipation rate were mainly located at the inlet and outlet of the rotating impeller and static impeller. The main reason is due to the rotor-stator interaction. The turbulence dissipation rate at the suction and pressure surfaces of blade on the first-stage rotating impeller was increased with the increase of flow rate, the turbulence dissipation rate from the inlet to the middle of the outlet was almost zero, and the turbulence dissipation rate on the suction surface was increased gradually from the hub to the rim of the blade. The overall turbulence dissipation rate in the static impeller was greater than that in the rotating impeller and was decreased with the increase in the flow rate gradually. The main reason is that the sizes of vortices in the static impeller are much larger than that in the rotating impeller. However, the sizes of vortices both in the static and rotating impeller are decreased with the decrease of flow rate due to the enhancement of the impeller binding effect to fluid.

(2) On the inlet section of the first-stage rotating impeller of the multiphase pump, the turbulence dissipation rate was increased gradually from the hub to the rim, on the middle and outlet sections, the turbulence dissipation rate was decreased firstly and then increased from the hub to the rim. From the hub to 0.5 times the blade height on the inlet section and from the hub to the rim on the middle section of the first-stage rotating impeller of the 
multiphase pump, the turbulence dissipation rate at a large flow rate was greater than that at a small flow rate generally, while the opposite trend appeared from 0.5 times the blade height to the rim on the inlet section and from the rub to the rim on the outlet section.

(3) On different outlet sections of the first-stage rotating impeller of the multiphase pump, the turbulence dissipation rate was unevenly distributed in the circumferential direction, with the maximum at 0.9 times the design flow rate and the minimum at 1.5 times, and there were four turning points which is the same as the number of impeller blades on the turbulence dissipation rate distribution at 0.9 times the design flow rate and at 0.5 times the blade height. This phenomenon indicates that the number of rotating impellers has great influence on the value of the turbulence dissipation rate.

(4) For the purpose of increasing the efficiency of the multiphase pump in the next design and optimization process, an important issue that needs direct attention is the optimization of the diffuser blade shape, since the present study found that a large intensity of the turbulence dissipation rate is mostly in the area of the diffuser.

Author Contributions: Conceptualization, G.S. and X.L.; methodology, G.S. and Z.H.; software, Z.H. and G.S.; validation, Z.H. and G.S.; formal analysis, H.W.; investigation, Z.H. and H.W.; resources, G.S. and X.L.; data curation, Z.H. and H.W.; writing-original draft preparation, G.S.; writing-review and editing, Z.H.; visualization, Z.H. and G.S.; supervision, G.S. and X.L.; project administration, G.S. and X.L.; funding acquisition, X.L. All authors have read and agreed to the published version of the manuscript.

Funding: This work was supported by the National Key Research and Development Program (2018YFB0905200), Open Research Fund Program of State Key Laboratory of Hydroscience and Engineering (sklhse-2021-E-03), Education department key project of Sichuan province of China (Grant No. 17ZA0366), the Key scientific research fund of Xihua University of China (Grant No.Z1510417), Open Research Subject of Key Laboratory of Fluid and Power Machinery, Ministry of Education (Grant No. LTDL2020-008), the National Natural Science Foundation of China (Grant Nos. 52079140, 51479093), the National Key Research and Development Program of China (Grant No. 2017YFC0404200), the Key Research and Development Program of Tianjin (Grant No. 18YFZCSF00310), the Key Laboratory of Fluid and Power Machinery (Xihua University) Ministry of Education (Grant Nos. SZJJ2014-045, SZJJ-2018-125).

Institutional Review Board Statement: Not applicable.

Informed Consent Statement: Not applicable.

Data Availability Statement: All the data is already in the article.

Conflicts of Interest: The authors declare no conflict of interest.

\section{References}

1. Kim, J.; Lee, H.; Yoon, J.; Lee, K.; Lee, Y.; Choi, Y. Multi Objective Optimization of a Multiphase Pump for Offshore Plants. In Proceedings of the ASME 2014 4th Joint Us-European Fluids Engineering Division Summer Meeting, Chicago, IL, USA, 3-7 August 2014.

2. Shi, G.; Liu, Z.; Xiao, Y.; Yang, H.; Li, H.; Liu, X. Effect of the inlet gas void fraction on the tip leakage vortex in a multiphase pump. Renew. Energy 2020, 150, 46-57. [CrossRef]

3. Etchepare, R.; Oliveira, H.; Nicknig, M.; Azevedo, A.; Rubio, J. Nanobubbles: Generation using a multiphase pump, properties and features in flotation. Miner. Eng. 2017, 112, 19-26. [CrossRef]

4. Azevedo, A.; Rubio, J.; Oliveira, H. Nanobubbles generation in a high-rate hydrodynamic cavitation tube. Miner. Eng. 2018, 116, 32-34.

5. Lim, A.E.; Lim, C.Y.; Lam, Y.C.; Lim, Y.H. Effect of microchannel junction angle on two-phase liquid-gas Taylor flow. Chem. Eng. Sci. 2019, 202, 417-428. [CrossRef]

6. Wu, L.Y.; Liu, L.B.; Han, X.T.; Li, Q.-W.; Yang, W.-B. Numerical simulation on dynamic behaviors of bubbles flowing through bifurcate T-junction in microfluidic device. Chin. Phys. B 2019, 28, 421-431. [CrossRef]

7. Ammann, M.; Rossler, E.; Strekowski, R.; George, C. Nitrogen dioxide multiphase chemistry: Uptake kinetics on aqueous solutions containing phenolic compounds. Phys. Chem. Chem. Phys. 2005, 7, 2513-2518. [CrossRef] [PubMed]

8. Xiong, Q.; Lim, A.E.; Lim, Y.; Duan, H. Dynamic Magnetic Nanomixers for Improved Microarray Assays by Eliminating Diffusion Limitation. Adv. Healthc. Mater. 2019, 8, 1801022. [CrossRef] [PubMed] 
9. Abolhasani, M.; Jensen, K.F. Oscillatory multiphase flow strategy for chemistry and biology. Lab Chip 2016, 16, 2775-2784. [CrossRef] [PubMed]

10. Yu, Z. Characteristic Analysis of Unsteady Gas-liquid Two-phase Flow in a Multiphase Rotodynamic Pump. Trans. Chin. Soc. Agric. Mach. 2013, 44, 66-69.

11. Suh, J.; Kim, J.; Choi, Y.; Kim, J.; Joo, W.; Lee, K. Multi-Objective Optimization of the Hydrodynamic Performance of the Second Stage of a Multi-Phase Pump. Energies 2017, 10, 1334. [CrossRef]

12. Zhang, J.; Li, Y.; Vafai, K.; Zhang, Y. An investigation of the flow characteristics of multistage multiphase pumps. Int. J. Numer. Methods Heat Fluid Flow 2018, 28, 763-784. [CrossRef]

13. Liu, X.; Hu, Q.; Wang, H.; Jiang, Q.; Shi, G. Characteristics of unsteady excitation induced by cavitation in axial-flow oil-gas multiphase pumps. Adv. Mech Eng. 2018, 10, 1-8. [CrossRef]

14. Shi, G.; Liu, Z.; Liu, X.; Xiao, Y.; Tang, X. Phase Distribution in the Tip Clearance of a Multiphase Pump at Multiple Operating Points and Its Effect on the Pressure Fluctuation Intensity. Processes 2021, 9, 556. [CrossRef]

15. Zhang, W.; Xie, X.; Zhu, B.; Ma, Z. Analysis of phase interaction and gas holdup in a multistage multiphase rotodynamic pump based on a modified Euler two-fluid model. Renew. Energy 2021, 164, 1496-1507. [CrossRef]

16. Liu, M.; Tan, L.; Cao, S. Dynamic mode decomposition of gas-liquid flow in a rotodynamic multiphase pump. Renew. Energy 2019, 139, 1159-1175. [CrossRef]

17. Li, Y.; Yu, Z.; Zhang, W.; Yang, J.; Ye, Q. Analysis of bubble distribution in a multiphase rotodynamic pump. Eng. Appl. Comput. Fluid Mech. 2019, 13, 551-559.

18. Zhang, J.; Cai, S.; Li, Y.; Zhu, H.; Zhang, Y. Visualization study of gas-liquid two-phase flow patterns inside a three-stage rotodynamic multiphase pump. Exp. Therm. Fluid Sci. 2016, 70, 125-138. [CrossRef]

19. Parikh, T.; Mansour, M.; Thévenin, D. Investigations on the effect of tip clearance gap and inducer on the transport of air-water two-phase flow by centrifugal pumps. Chem. Eng. Sci. 2020, 218, 1-21. [CrossRef]

20. Yan, D.; Kovacevic, A.; Tang, Q.; Rane, S.; Zhang, W. Numerical modeling of twin-screw pumps based on computational fluid dynamics. Proc. Inst. Mech. Eng. Part C J. Mech. Eng. Sci. 2017, 231, 4617-4634. [CrossRef]

21. Zhang, J.; Tan, L. Energy performance and pressure fluctuation of a multiphase pump with different gas volume fractions. Energies 2018, 11, 1216. [CrossRef]

22. Fu, X.; Zuo, Z.; Chang, H.; Li, D.; Wang, H.; Wei, X. Mechanism of low frequency high amplitude pressure fluctuation in a pump-turbine during the load rejection process. J. Hydraul. Res. 2021, 59, 280-297.

23. Zhang, J.; Li, Y.; Cai, S.; Zhu, H.; Zhang, Y. Investigation of gas-liquid two-phase flow in a three-stage rotodynamic multiphase pump via numerical simulation and visualization experiment. Adv. Mech. Eng. 2016, 8. [CrossRef]

24. Verde, W.M.; Biazussi, J.L.; Sassim, N.A.; Bannwart, A.C. Experimental study of gas-liquid two-phase flow patterns within centrifugal pumps impellers. Exp. Therm. Fluid Sci. 2017, 85, 37-51. [CrossRef]

25. Zhang, J.; Cai, S.; Zhu, H.; Zhang, Y. Experimental investigation of the flow at the entrance of a rotodynamic multiphase pump by visualization. J. Pet. Sci. Eng. 2015, 126, 254-261. [CrossRef]

26. Yang, X.; Hu, C.; Hu, Y.; Qu, Z. Theoretical and experimental study of a synchronal rotary multiphase pump at very high inlet gas volume fractions. Appl. Therm. Eng. 2017, 110, 710-719. [CrossRef]

27. Xu, Y.; Cao, S.; Sano, T.; Wakai, T.; Reclari, M. Experimental Investigation on Transient Pressure Characteristics in a Helico-Axial Multiphase Pump. Energies 2019, 12, 461. [CrossRef]

28. Ertürk, N.; Vernet, A.; Pallares, J.; Castilla, R.; Raush, G. Small-scale characteristics and turbulent statistics of the flow in an external gear pump by time-resolved PIV. Flow Meas. Instrum. 2013, 29, 52-60. [CrossRef]

29. Sharp, K.V.; Adrian, R.J. PIV study of small-scale flow structure around a Rushton turbine. Fluid Mech. Transp. Phenom. 2001, 47, 766-778. [CrossRef]

30. Delafosse, A.; Collignon, M.L.; Crine, M.; Toye, D. Estimation of the turbulent kinetic energy dissipation rate from 2D-PIV measurements in a vessel stirred by an axial Mixel TTP impeller. Chem. Eng. Sci. 2011, 66, 1728-1737. [CrossRef]

31. Erturk, N.; Vernet, A.; Castilla, R.; Gamez-Montero, P.J.; Ferre, J.A. Experimental analysis of the flow dynamics in the suction chamber of an external gear pump. Int. J. Mech. Sci. 2011, 53, 135-144. [CrossRef]

32. Castilla, R.; Wojciechowski, J.; Gamez-Montero, P.J.; Vernet, A.; Codina, E. Analysis of the turbulence in the suction chamber of an external gear pump using time resolved particle image velocimetry. Flow Meas. Instrum. 2008, 19, 377-384. [CrossRef]

33. Shi, G.; Liu, Z.; Xiao, Y.; Wang, Z.; Luo, Y.; Luo, K. Energy conversion characteristics of multiphase pump impeller analyzed based on blade load spectra. Renew. Energy 2020, 157, 9-23. [CrossRef]

34. Li, D.; Song, Y.; Lin, S.; Wang, H.; Qin, Y.; Wei, X. Effect mechanism of cavitation on the hump characteristic of a pump-turbine. Renew. Energy 2020, 167, 369-383. [CrossRef]

35. Ghorani, M.M.; Haghighi, M.H.S.; Maleki, A.; Riasi, A. A numerical study on mechanisms of energy dissipation in a pump as turbine (PAT) using entropy generation theory. Renew. Energy 2020, 162, 1036-1053. [CrossRef]

36. Wilcox, D.C. Turbulence Modeling for CFD; DCW Industries: La Canada, CA, USA, 1998.

37. Menter, F.R. Two-equation eddy-viscosity turbulence models for engineering applications. AIAA J. 1994, 32, 1598-1605. [CrossRef] 